\title{
Bismuth (III) Salts Promoted and Ionic Liquid Assisted an Efficient and Environmentally Benign One-Pot Synthesis of 1,5-Benzodiazepine Derivatives
}

\author{
Atul Chaskar, ${ }^{1}$ Latika Patil, ${ }^{2}$ Kiran Phatangare, ${ }^{2}$ Vikas Padalkar, ${ }^{2}$ and Santosh Takale ${ }^{2}$ \\ ${ }^{1}$ Department of Chemistry, National Taiwan University, 106 Taipei, Taiwan \\ ${ }^{2}$ Department of Chemistry, C. K. Thakur Research Centre, Navi Mumbai 410206, India
}

Correspondence should be addressed to Atul Chaskar, achaskar@rediffmail.com

Received 17 January 2011; Accepted 28 February 2011

Academic Editor: B. Das

Copyright (C) 2011 Atul Chaskar et al. This is an open access article distributed under the Creative Commons Attribution License, which permits unrestricted use, distribution, and reproduction in any medium, provided the original work is properly cited.

1,5-Benzodiazepine derivatives were synthesized by the condensation reactions of $o$-phenylenediamine and ketones catalyzed by bismuth (III) salts under mild conditions. This method is easy, efficient, environment and eco-friendly, free of toxic catalysts, and gives good to excellent yields of 1, 5-benzodiazepines.

\section{Introduction}

The synthesis of 1,5-benzodiazepines and their derivatives have attracted considerable attention of researchers, including pharmaceutical and organic synthetic chemists, in recent years because of their medicinal properties namely antianxiety, hypnotic, antidepressive, tranquilizing, antiinflammatory, anticonvulsant, antifeedant, antibacterial, and analgesic agents [1-4]. In addition, 1,5-benzodiazepines are valuable synthons used for the preparation of other fused ring compounds such as triazolo, oxazino or furanobenzodiazepines $[5,6]$. Benzodiazepines derivatives are also used in industry as dyes for acrylic fibers in photography [7].

Due to their wide range of pharmacological activities and industrial and synthetic applications, the development of practical and green protocols continues to be a challenging endeavour in synthetic chemistry. In recent years, many methods for their preparation are reported in the literature. These include condensation reactions of $o$-phenylenediamine with $\alpha, \beta$-unsaturated carbonyl compounds [8], $\beta$-haloketones [9], $\beta$-aminoketones [10] or ketones promoted by $\mathrm{BF}_{3} \cdot \mathrm{OEt}_{2}$ [11], $\mathrm{NaBH}_{4}$ [12], polyphosphoric acid or $\mathrm{SiO}_{2}$ [13], ceric ammonium nitrate (CAN) [14], $\mathrm{MgO} / \mathrm{POCl}_{3}$ [15], $\mathrm{Yb}(\mathrm{OTf})_{3}$ [16], $\mathrm{Al}_{2} \mathrm{O}_{3} / \mathrm{P}_{2} \mathrm{O}_{5}$ or $\mathrm{AcOH}$ under microwave conditions [17], Amberlyst15 in ionic liquid [18], $\mathrm{CeCl}_{3} / 7 \mathrm{H}_{2} \mathrm{O} / \mathrm{NaI}$ supported on
TABLE 1: Influence of catalysts on preparation of 1,5-benzodiazepines from o-phenylendiamine and acetone ${ }^{\mathrm{a}}$.

\begin{tabular}{lccc}
\hline Entry & Catalyst & Time & Yield $^{\mathrm{b}}$ \\
\hline 1 & - & $20 \mathrm{~h}$ & trace \\
2 & $\mathrm{HCl}$ & $3 \mathrm{~h}$ & 79 \\
3 & $\mathrm{SiO}_{2}$ & $3 \mathrm{~h}$ & 91 \\
4 & $\mathrm{YbCl}_{3}$ & $1.5 \mathrm{~h}$ & 85 \\
5 & {$\left[\mathrm{HMIm} \mathrm{BF}_{4}\right.$} & $3 \mathrm{~h}$ & 43 \\
6 & Amberlyst-15 & $3.5 \mathrm{~h}$ & 90 \\
7 & Polyphosphoric acid & $3 \mathrm{~h}$ & 83 \\
8 & Bismuth (III) salts & $1 \mathrm{~h}$ & 95 \\
\hline
\end{tabular}

${ }^{a}$ Reaction condition: $o$-phenylendiamine $(0.01 \mathrm{~mol})$, acetone $(0.02 \mathrm{~mol})$, Bismuth (III) salts $(0.002 \mathrm{~mol})$, Ionic liquid $(2 \mathrm{~mL})$, and room temperature. ${ }^{\mathrm{b}}$ Isolated Yield.

silica gel [19], $\operatorname{InBr}_{3}$ [20], 1-butyl-3-methylimidazolium bromide ([bmim] Br) [21], Sc(OTf $)_{3}[22]$, and $\mathrm{Nb}(\mathrm{Cl})_{3}[23]$. However, many of these methodologies have one or more shortcomings, such as long reaction time, poor yields of the products, drastic reaction conditions, occurrence of several side products, expensive reagents, high catalyst loading, and tedious workup procedures.

Bismuth (III) salts have emerged in the recent years as "eco-friendly" reagents suitable for green chemistry. They 
TABLE 2: Bismuth (III) salts catalysed condensation of $o$-phenylendiamine with different ketones ${ }^{\mathrm{a}}$.

Entry

1

Acetone

2

3

4

2-butanone

2-pentanone

3-pentanone

5

4-methyl-2-pentanone

3-methyl-2-butanone

Cyclopentanone

Cyclohexanone

Acetophenone
Yield $^{\mathrm{a}}$

$\mathrm{Mp}\left({ }^{\circ} \mathrm{C}\right)$<smiles>CC1=Nc2ccccc2NC(C)(C)C1</smiles>

95<smiles>CCC1(C)Nc2ccccc2N=C(C)C1C</smiles>

90

137<smiles>CCCC1(C)Nc2ccccc2N=C(C)C1CC</smiles>

140

92

143

91

118

93

119<smiles>CC(C)C1=Nc2ccccc2NC(C)(C(C)C)C1</smiles><smiles>c1ccc2c(c1)N=C1CCCC1C1(CCCC1)N2</smiles>

94

135<smiles>c1ccc2c(c1)N=C1CCCCC1C1(CCCCC1)N2</smiles>

88

138<smiles>CC1(c2ccccc2)CC(c2ccccc2)=Nc2ccccc2N1</smiles>

89

${ }^{a}$ Reaction conditions: $o$-phenylenediamine $(0.01 \mathrm{~mol})$, ketones $(0.02 \mathrm{~mol})$, Bismuth (III) salts $(0.002 \mathrm{~mol})$, ionic liquid $(2 \mathrm{~mL})$, room temperature, and time $1 \mathrm{hr} .{ }^{\mathrm{b}}$ Isolated Yield. 


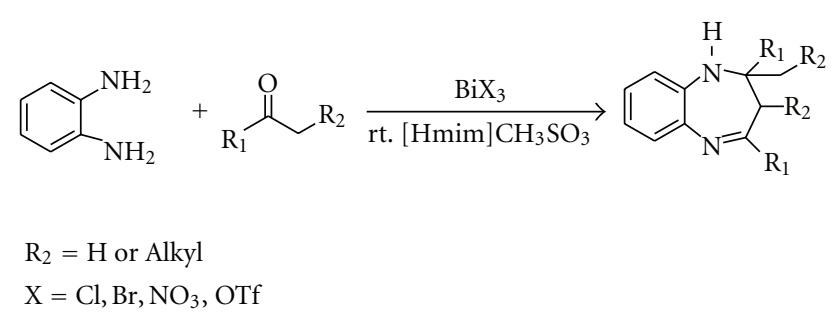

SCHEMe 1

have received considerable attention as mild Lewis acids [24-27] for an array of organic transformations because the catalysts are inexpensive, relatively nontoxic, moisture and air tolerant, environmentally benign, and commercially available. Ionic liquid is used as an alternative to traditional solvents for organic reactions particularly in the area of green chemistry.

Thus, considering the advantages and applications of bismuth (III) salts and ionic liquid, and as part of our ongoing project to explore the catalytic activities of bismuth (III) salts in organic transformations [28], we attempted the convenient and practical synthesis of 1,5 benzodiazepines using bismuth (III) salts (Scheme 1).

In order to investigate the catalytic efficiency of bismuth (III) salts and compare it with different acid catalysts, the condensation of $o$-phenylendiamine with acetone in presence of different catalysts at room temperature was investigated, and results are shown in Table 1.

The results mentioned in Table 1 demonstrate the effective use of bismuth (III) salts and ionic liquid for the synthesis of 1,5-benzodiazepines.

Encouraged by the results obtained in the above reaction and in order to prove the generality and scope of this new protocol, a wide verity of ketones were evaluated and the results are summarised in Table 2. Aromatic, aliphatic, and cyclic ketones reacted with $o$-phenylenediamine, affording the corresponding 1,5-benzodiazepines in good to excellent yields. Cyclic ketones gave fused ring benzodiazepines. Products were characterized by ${ }^{1} \mathrm{H}-\mathrm{NMR},{ }^{13} \mathrm{C} \mathrm{NMR}$, and Mass and physical constant. Physical and spectral data of known compounds are in good accordance with those reported in the literature.

Further, we extended this protocol to substituted $o$ phenylenediamine, and we have observed that the electron donating group increases the rate of reaction, whereas electron withdrawing group decreases the rate of reaction and yield of product.

\section{Conclusion}

In conclusion, we have demonstrated here a new and efficient procedure for the synthesis of 1,5-benzodiazepine derivatives catalyzed by bismuth (III) salts in ionic liquid. The advantages of our protocol are easy workup, fast reaction rate, and mild reaction condition with good yield, which make the method an attractive and a useful contribution to the present methodologies.

\section{Experimental}

All commercial reagents were used as received without purification, and all solvents were reagent grade. The reaction was monitored by TLC using on $0.25 \mathrm{~mm}$ E-Merck silica gel 60 F254 precoated plates, which were visualized with UV light. Melting points were taken in open capillaries. The IR spectra were recorded on a PerkinElmer 257 spectrometer using $\mathrm{KBr}$ discs. ${ }^{1} \mathrm{H}$ NMR and ${ }^{13} \mathrm{C}$ NMR spectra were recorded on a VXR-300 MHz instrument using TMS as an internal standard.

3.1. General Experimental Procedure. A mixture of ophenylenediamine $(0.01 \mathrm{~mol})$, ketone $(0.02 \mathrm{~mol})$, and bismuth (III) salts $(0.002 \mathrm{~mol})$ in ionic liquid $(2 \mathrm{~mL})$ was stirred at room temperature for $1 \mathrm{hr}$. After completion of reaction, as monitored by TLC, the reaction mixture was extracted with ethyl acetate $(2 \times 10 \mathrm{~mL})$. The combined organic extract were washed with distilled water, dried over $\mathrm{Na}_{2} \mathrm{SO}_{4}$, and removal of the solvent under reduced pressure furnished the crude product, which was loaded on the silica column and illute with Ethyl acetate-hexane (3:7) solvent system to get pure diazepine.

Representative Spectral Data for 2, 2,4-Trimethyl-2,3-dihydro1H-1,5-benzodiazepine.

IR (KBr). $3290(\mathrm{NH}), 1642(\mathrm{C}=\mathrm{N}), 1592(\mathrm{Ar}) \mathrm{cm}^{-1}$;

${ }^{1} \mathrm{H} N M R\left(300 \mathrm{MHz}, C D C_{l 3}\right) . \delta 1.34\left(\mathrm{~s}, 6 \mathrm{H}, 2 \mathrm{C}_{\mathrm{H} 3}\right), 2.20(\mathrm{~s}$, $\left.2 \mathrm{H}, \mathrm{C}_{\mathrm{H} 2}\right), 2.36\left(\mathrm{~s}, 3 \mathrm{H}, \mathrm{C}_{\mathrm{H} 3}\right), 3.45$ (brs, $\left.1 \mathrm{H}, \mathrm{NH}\right), 6.62-7.21$ (m, $4 \mathrm{H}, \mathrm{Ar}$ );

${ }^{13} \mathrm{C} \mathrm{NMR}\left(300 \mathrm{MHz}, \mathrm{CDCl}_{3}\right) . \delta 171.6,140.4,138.0,126.9$, $125.3,121.8,121.6,68.1,45.4,30.6,29.5,29.5$;

GC/MS. $\mathrm{M}^{+}$188. $\mathrm{Mp} 125^{\circ} \mathrm{C}$.

\section{Acknowledgments}

The authors greatly appreciate the financial support of University Grand Commission, New Delhi, and University of Mumbai. They are thankful to Dr. S. T. Gadade, Principal, C. K. Thakur College, for their generous support.

\section{References}

[1] H. Schutz, Benzodiazepines, Springer, Heidelberg, Germany, 1982.

[2] J. K. Landquist, in Comprehensive Heterocyclic Chemistry, A. R. Katritzky and C. W. Rees, Eds., vol. 1, p. 116, Pergamon, Oxford, UK, 1984.

[3] L. O. Randall and B. Kamal, in Benzodiazepines, S. Garattini, E. Mussini, and L. O. Randall, Eds., p. 27, Raven Press, New York, NY, USA, 1973.

[4] J. R. D. Baun, F. M. Pallos, and D. R. Baker, "5furoyl-2,2,4-trimethyl-1,4-dihydro-1H-1,5-benzodiazepine as an anti-inflammatory agent," US patent no. 3,978,227, 1976; Chem. Abstr. 1977, 86, 5498d. 
[5] M. C. Aversa, A. Ferlazzo, P. Giannetto, and F. H. Kohnke, "A convenient synthesis of novel $[1,2,4]$ triazolo[4,3a] $[1,5]$ benzodiazepine derivatives," Synthesis, vol. 3, pp. 230$231,1986$.

[6] A. Chimirri, S. Grasso, R. Ottana, G. Romeo, and M. Zapala, "Synthesis and stereochemistry of Novel $[1,2,4]$ oxadiazolo[4,5-][1,5]benzodiazepine aerivatives," Journal of Heterocyclic Chemistry, vol. 27, no. 2, pp. 371-374, 1990.

[7] R. C. Haris and J. M. Straley, "Cationic polymethine dyes for acrylic fibers," US patent no. 1,537,757, 1968; Chem. Abstr. 1970, 73, 100054w.

[8] P. Stahlofen and W. Ried, "Über heterocyclische Siebenringsysteme, V. Umsetzung von o-Phenylendiamin mit, $\beta$ Ungesttigten Carbonylverbindungen," Chemische Berichte, vol. 90, pp. 815-824, 1957.

[9] W. Ried and E. Torinus, "Über heterocyclische Siebenringsysteme, X. Synthesen kondensierter 5-, 7- und 8-gliedriger Heterocyclen mit 2 Stickstoffatomen," Chemische Berichte, vol. 92, pp. 2902-2916, 1959.

[10] R. Gheorghe, E. Comanita, and B. Bogdan, "Synthesis and reactivity of mannich bases. XIV. Base-catalyzed cyclocondensation of $\beta$-aminoketones to 1,5-benzodiazepines and 1,4naphthodiazepines," Acta Chimica Slovenica, vol. 49, no. 3, pp. 575-585, 2002.

[11] J. A. L. Herbert and H. Suschitzky, "Syntheses of heterocyclic compounds. Part XXIX. Substituted 2,3-dihydro-1H-1, 5benzodiazepines," Journal of the Chemical Society, Perkin Transactions, vol. 1, pp. 2657-2661, 1974.

[12] H. R. Morales, A. Bulbarela, and R. Contreras, "New synthesis of dihydro-and tetrahydro-1,5-benzodiazepines by reductive condensation of o-phenylenediamine and ketones in the presence of sodium borohydride," Heterocycles, vol. 24, no. 1, pp. 135-139, 1986.

[13] D. I. Jung, T. W. Choi, Y. Y. Kim et al., "Synthesis of 1,5benzodiazepine derivatives," Synthetic Communications, vol. 29, no. 11, pp. 1941-1951, 1999.

[14] R. Varala, R. Enugala, S. Nuvula, and S. R. Adapa, "Ceric ammonium nitrate (CAN) promoted efficient synthesis of 1,5-benzodiazepine derivatives," Synlett, no. 7, pp. 1009-1014, 2006.

[15] M. S. Balakrishna and B. Kaboudin, "A simple and new method for the synthesis of 1,5-benzodiazepine derivatives on a solid surface," Tetrahedron Letters, vol. 42, no. 6, pp. 1127$1129,2001$.

[16] M. Curini, F. Epifano, M. C. Marcotullio, and O. Rosati, "Ytterbium triflate promoted synthesis of 1,5-benzodiazepine derivatives," Tetrahedron Letters, vol. 42, no. 18, pp. 3193 3195, 2001.

[17] M. Pozarentzi, J. Stephanidou-Stephanatou, and C. A. Tsoleridis, "An efficient method for the synthesis of 1,5benzodiazepine derivatives under microwave irradiation without solvent," Tetrahedron Letters, vol. 43, no. 9, pp. 1755-1758, 2002.

[18] J. S. Yadav, B. V. S. Reddy, B. Eshwaraiah, and K. Anuradha, "Amberlyst-15®: a novel and recyclable reagent for the synthesis of 1,5-benzodiazepines in ionic liquids," Green Chemistry, vol. 4, no. 6, pp. 592-594, 2002.

[19] G. Sabitha, G. S. Kiran Kumar Reddy, K. Bhaskar Reddy, N. Mallikarjuna Reddy, and J. S. Yadav, "A new, efficient and environmentally benign protocol for the synthesis of 1,5benzodiazepines using cerium(III) chloride/sodium iodide supported on silica gel," Advanced Synthesis and Catalysis, vol. 346, no. 8, pp. 921-923, 2004.
[20] J. S. Yadav, B. V. S. Reddy, S. Praveenkumar, and K. Nagaiah, "Indium(III) bromide: a novel and efficient reagent for the rapid synthesis of 1,5-benzodiazepines under solvent-free conditions," Synthesis, no. 3, pp. 480-484, 2005.

[21] D. V. Jarikote, S. A. Siddiqui, R. Rajagopal, T. Daniel, R. J. Lahoti, and K. V. Srinivasan, "Room temperature ionic liquid promoted synthesis of 1,5-benzodiazepine derivatives under ambient conditions," Tetrahedron Letters, vol. 44, no. 9, pp. 1835-1838, 2003.

[22] S. K. De and R. A. Gibbs, "Scandium(III) triflate as an efficient and reusable catalyst for synthesis of 1,5-benzodiazepine derivatives," Tetrahedron Letters, vol. 46, no. 11, pp. 18111813, 2005.

[23] S. T. Gao, W. H. Liu, J. J. Ma, C. Wang, and Q. Liang, "NbCl as an efficient catalyst for the synthesis of 1,5-benzodiazepine derivatives," Synthetic Communications, vol. 39, no. 18, pp. 3278-3284, 2009.

[24] G. Sabitha, R. S. Babu, E. V. Reddy, and J. S. Yadav, "A novel, efficient, and selective cleavage of acetals using bismuth(III) chloride," Chemistry Letters, no. 9, pp. 1074-1075, 2000.

[25] H. Firouzabadi, I. Mohammadpoor-Baltork, and S. Kolagar, "A rapid, selective, and efficient method for deprotection of silyl ethers catalyzed by bismuth(III) salts," Synthetic Communications, vol. 31, no. 6, pp. 905-909, 2001.

[26] Y. Matano and T. Ikegami, in Organobismuth Chemistry, H. Suzuki and Y. Manato, Eds., chapter 2, pp. 21-245, Elsevier, New York, NY, USA, 2001.

[27] N. M. Leonard, L. C. Wieland, and R. S. Mohan, "Applications of bismuth(III) compounds in organic synthesis," Tetrahedron, vol. 58, no. 42, pp. 8373-8397, 2002.

[28] A. C. Chaskar, B. P. Langi, A. Deorukhkar, and H. Deokar, "Bismuth chloride-sodium nitrite: a novel reagent for chemoselective N-nitrosation," Synthetic Communications, vol. 39, no. 4, pp. 604-612, 2009. 


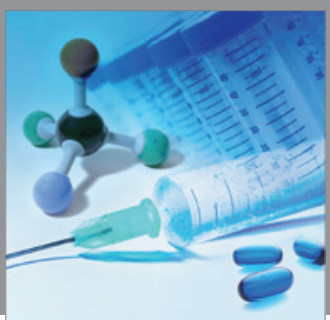

International Journal of

Medicinal Chemistry

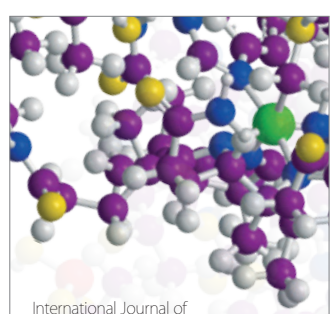

Carbohydrate Chemistry

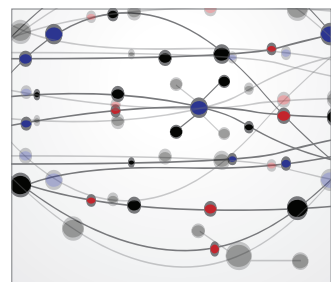

The Scientific World Journal
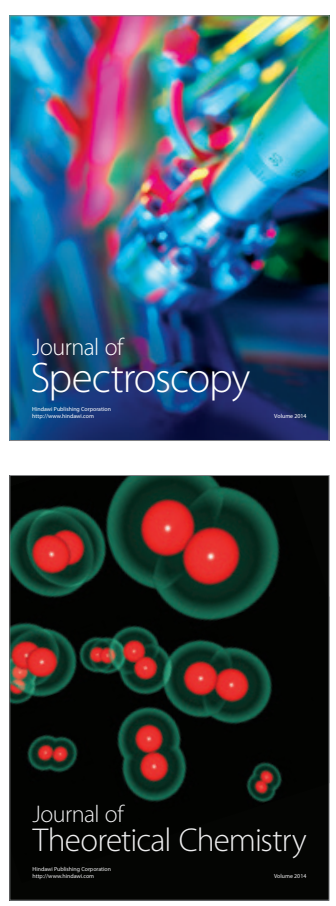
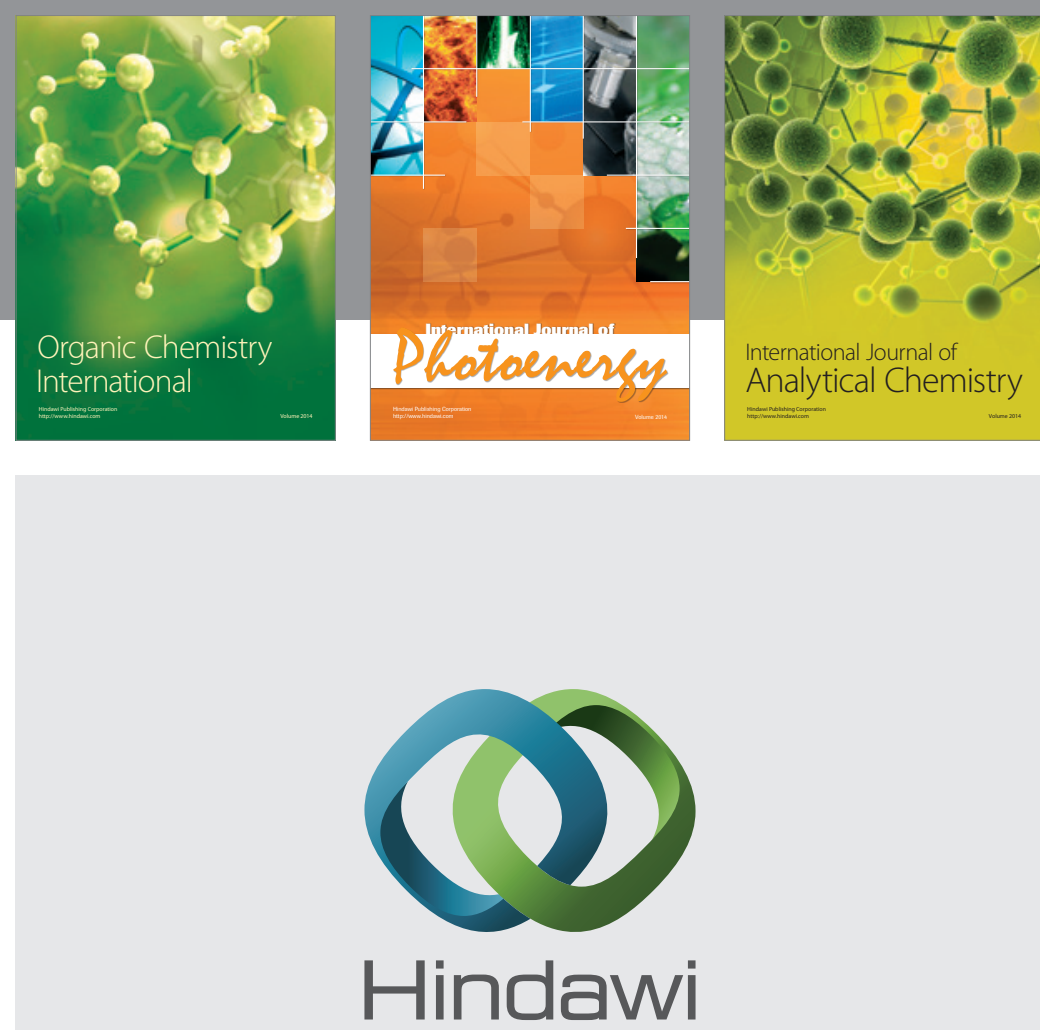

Submit your manuscripts at

http://www.hindawi.com
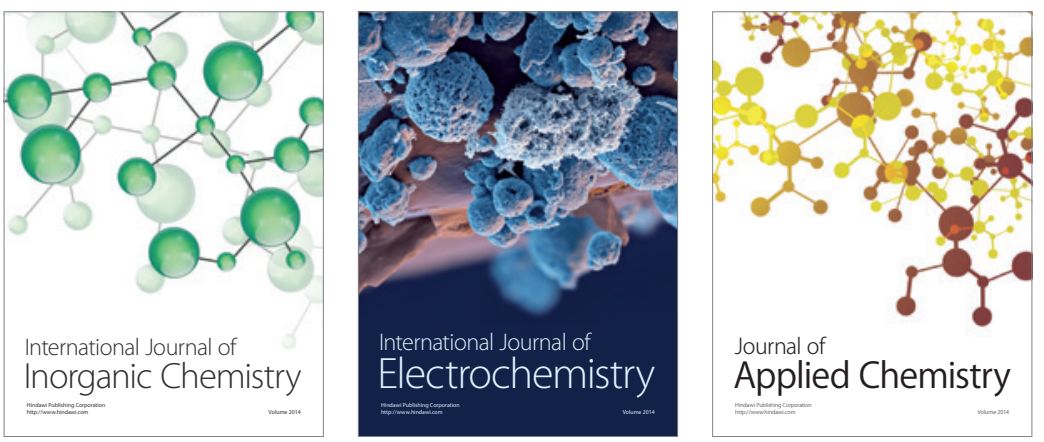

Journal of

Applied Chemistry
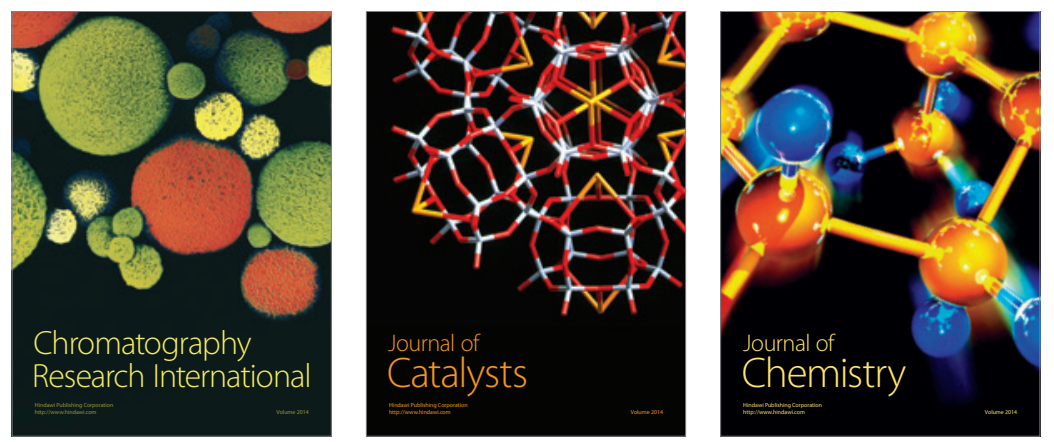
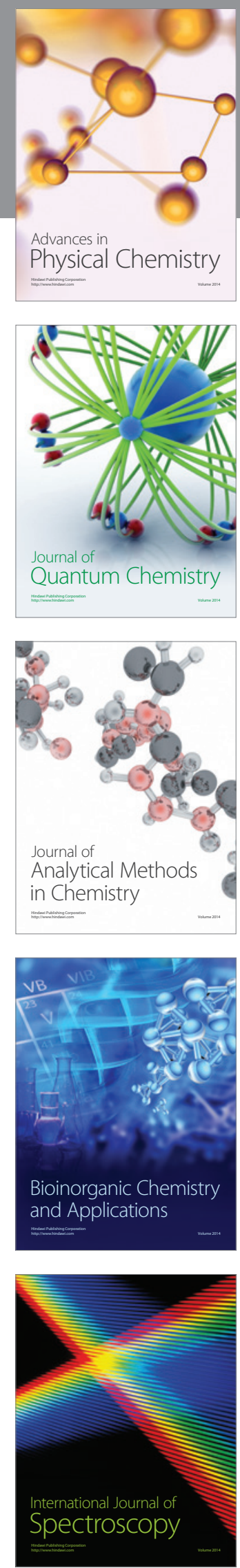